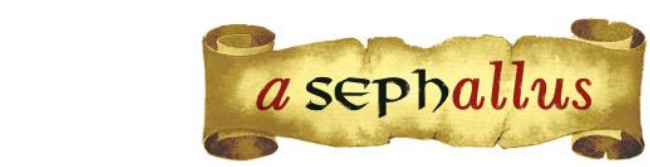

Revista aSEPHallus de Orientação Lacaniana

Núcleo Sephora de Pesquisa sobre o Moderno e o Contemporâneo

ISSN $1809-709 \mathrm{X}$

\title{
Adolescência e saber no contexto das tecnologias digitais: há transmissão possível?
}

Nádia Laguárdia de Lima

Psicóloga pela Universidade Federal de Minas Gerais / UFMG (Minas Gerais, Brasil)

Doutora em Educação pela Universidade Federal de Minas Gerais / UFMG (Minas Gerais, Brasil)

Pós-doutora em Teoria Psicanalítica pela Universidade Federal do Rio de Janeiro / UFRJ (Rio de Janeiro,

Brasil)

Professora do Departamento de Psicologia e do Programa de Pós-Graduação em Psicologia da Universidade Federal de Minas Gerais / UFMG (Minas Gerais, Brasil)

Coordenadora do Laboratório de Psicologia e Educação do Departamento de Psicologia da Universidade

Federal de Minas Gerais / UFMG (Minas Gerais, Brasil) e da Pesquisa "Educação, subjetividade e cultura digital" financiada pela Coordenação de Aperfeiçoamento de Pessoal de Nível Superior (CAPES)

E-mail: nadia.laguardia@gmail.com

\section{Daniela Teixeira Dutra Viola}

Psicóloga pela Universidade Federal de Minas Gerais / UFMG (Minas Gerais, Brasil) Doutora em Psicologia pela Universidade Federal de Minas Gerais / UFMG (Minas Gerais, Brasil) Mestre em Psicologia pela Universidade Federal de Minas Gerais / UFMG (Minas Gerais, Brasil)

E-mail: daniela.dutraviola@gmail.com

Márcio Rimet Nobre

Psicólogo pela Universidade Federal de São João del Rei/UFS] (Minas Gerais, Brasil)

Mestre em Psicologia pela Pontifícia Universidade Católica de Minas Gerais/PUC Minas (Minas Gerais/Brasil)

Doutorando em Psicologia pela Universidade Federal de Minas Gerais / UFMG (Minas Gerais, Brasil)

Autor do livro Realidade virtual, realidade psíquica na pós-modernidade: um encontro com Freud na infinitude fantasística do ciberespaço Psicólogo clínico e consultor em planejamento estratégico de artistas, grupos e instituições culturais pela Ravel Cultural (Minas Gerais, Brasil) E-mail: marcionobre205@hotmail.com

Juliana Tassara Berni
Psicóloga pela Universidade Federal de Minas Gerais / UFMG (Minas Gerais, Brasil) Mestre em Psicologia pela Universidade Federal de Minas Gerais / UFMG (Minas Gerais, Brasil)

E-mail: jutassara@hotmail.com

\section{Helena Greco Lisita}

Psicóloga pela Pontifícia Universidade Católica de Minas Gerais/PUC Minas (Minas Gerais, Brasil) Mestre em Psicologia pela Universidade Federal de Minas Gerais / UFMG (Minas Gerais, Brasil)

Psicóloga da Clínica de Assistência psicossocial Freud Cidadão (Minas Gerais, Brasil) E-mail: helenagreco@globo.com

\begin{abstract}
Natália Fernandes Kelles
Psicóloga pela Pontifícia Universidade Católica de Minas Gerais/PUC Minas (Minas Gerais, Brasil) Mestranda em Psicologia pela Universidade Federal de Minas Gerais / UFMG (Minas Gerais, Brasil) Psicóloga da Universidade Federal de Minas Gerais / UFMG (Minas Gerais, Brasil) E-mail: nataliakelles@ufmg.br

Luiz Henrique de Carvalho Teixeira Graduando em Psicologia pela Universidade Federal de Minas Gerais / UFMG (Minas Gerais, Brasil) E-mail: Ihct luiz@live.com
\end{abstract}

Resumo: Este artigo apresenta uma reflexão embasada na psicanálise sobre o saber e sua transmissão na experiência dos adolescentes com a internet. Considerando a importância da transmissão geracional e da assimilação de saberes, bem como o lugar que os movimentos e as vivências virtuais ocupam na vida de grande parte dos jovens, intentamos compreender o estatuto da transmissão que é efetuada nesse âmbito. $O$ que buscam os adolescentes na internet hoje? Em que medida o acesso ilimitado à informação e ao conhecimento, 
propiciado pelo ciberespaço, contribui para a apreensão do saber? De que ordem é o endereçamento dos jovens aos conteúdos virtuais? Como se dá a transmissão de saber no contexto da cultura digital? Em vista dessas questões, levantadas a partir do que escutamos de alguns adolescentes num contexto de pesquisa e extensão, propomos discutir as relações dos sujeitos adolescentes com o saber em um mundo em que prevalece a comunicação virtual.

Palavras-chave: psicanálise; adolescência; psicanálise; saber; cultura digital; conversação.

\title{
Adolescence et savoir dans le contexte des technologies: existe-t-il une transmission possible?
}

Cet article présente une réflexion à propos du savoir et de sa transmission dans l'expérience des adolescents sur l'Internet. Compte tenu de l'importance de la transmission générationnelle et de l'assimilation des savoirs, aussi bien que la place que les expériences virtuelles occupent dans la vie de la plupart des jeunes, nous essayerons de comprendre le statut de la transmission qui se passe dans ce domaine. Qu'est-ce que les adolescents cherchent sur Internet? Dans quelle mesure un accès illimité à l'information et à la connaissance, rendu possible par le cyberespace, contribue à l'absoption du savoir? De quoi s'agit-il quand les jeunes s'adressent aux contenus virtuels? Comment la transmission du savoir dans la culture numérique a-t-elle lieu? Compte tenu de ces questions soulevées de ce que nous avons écouté de quelques adolescents dans un contexte de recherche et d'extension, nous proposons de discuter la relation d'adolescents avec le savoir dans un monde où la communication virtuelle est prévalante.

Mots-clés: psychoanalysis; adolescence; psychanalyse; savoir; culture numérique; conversation.

\begin{abstract}
Adolescence and knowledge in the context of digital technologies: is there a possible transmission?

This article presents a reflection, grounded in psychoanalysis, on knowledge and its transmission during an adolescent's experience with the internet. Considering the importance of generational transmission and knowledge assimilation, as well as the place occupied by virtual experiences in the lives of young individuals, we intend to understand the status of the transmission that is performed in this context. What are teenagers seeking on the internet these days? To what extent does the unlimited access to information, provided by the cyberspace, contribute to the apprehension of knowledge? Of which order is the relationship of the youth with the virtual content? How does the transmission of knowledge, in this context, happen? Using what we have collected from teenagers in a context of research, we propose to discuss the relationship of the adolescent subjects with knowledge in a world in which virtual communication is paramount.
\end{abstract}

Key-words: psychoanalyse; adolescence; psychoanalysis; knowledge; digital culture; conversation. 


\title{
Adolescência e saber no contexto das tecnologias digitais: há transmissão possível?
}

\author{
Nádia Laguárdia de Lima et al.
}

\section{Introdução}

A escola tem convocado profissionais de outros campos do saber a responderem sobre os impasses que os educadores vivenciam em suas práticas docentes. As principais queixas dos educadores referem-se aos atos de violência, ao uso de drogas, à hiperatividade, às manifestações de sexualidade e ao fracasso escolar entre adolescentes. Atualmente, acompanhamos um crescimento de queixas relacionadas ao uso excessivo e inadequado da internet feito pelos jovens. O fracasso escolar é, frequentemente, associado ao uso das tecnologias digitais. O fascínio despertado pelos dispositivos eletrônicos contrasta com o desinteresse crescente dos jovens pela aprendizagem escolar. A horizontalidade do acesso à informação corrobora para o declínio da autoridade do professor, agravando as dificuldades na transmissão pedagógica.

As inquietações e angústias dos educadores com relação à "juventude digital" permitem a entrada do psicanalista na escola, que interroga sobre essas novas formas de manifestação do malestar na cultura apresentadas no contexto escolar. O que esses impasses no campo educacional nos ensinam? De que ordem é o endereçamento dos jovens aos conteúdos virtuais? Existe transmissão de saber na internet? Quais as diferenças entre informação, conhecimento e saber?

Neste artigo, apresentaremos uma reflexão sobre o saber e sua transmissão na adolescência, no contexto das tecnologias digitais. Teremos como apoio para esta discussão a escuta de adolescentes em uma instituição de ensino, propiciada pelo projeto de pesquisa e extensão Conversação na escola: adolescentes e redes sociais. Esse projeto surgiu a partir da demanda de uma escola pública de educação básica em Belo Horizonte que tem vivenciado conflitos devido ao uso que os adolescentes fazem das redes sociais virtuais dentro e fora dos muros da escola, expondo, muitas vezes, alunos, docentes e a própria instituição. A preocupação é compartilhada com os pais dos alunos que recorrem à escola para se orientarem sobre o assunto e relatarem conflitos com os filhos, gerados por conversas de grupos de WhatsApp dos alunos, o uso excessivo de jogos e dispositivos eletrônicos, entre outros.

O projeto visa intervir junto aos adolescentes da escola, criando espaços de reflexão nos quais a utilização do ciberespaço possa ser interrogada pelos jovens. Buscamos investigar o uso que os adolescentes fazem dessas redes e criar espaços dialógicos entre eles, possibilitando o surgimento de questionamentos e reflexões, dando lugar às subjetividades no contexto coletivo (Lima, 2013). Acreditamos que, ao invés de buscar impedir o emprego das tecnologias digitais pelos jovens, é preciso buscar conhecer os usos que eles fazem destes dispositivos. Assim é possível localizar não somente os impasses, riscos e dificuldades, mas também os recursos e possibilidades existentes no uso do ciberespaço. 
Os grupos de conversação ocorrem semanalmente, em horário pré-estabelecido pela escola. Cada grupo é conduzido por um psicólogo e acompanhado por um aluno da graduação em Psicologia, responsável pelo registro dos encontros. A metodologia de conversação pode ser compreendida como uma associação livre coletivizada em que a oferta da palavra circula no grupo. A conversação é uma modalidade de pesquisa-intervenção criada por Jacques-Alain Miller no Centre Interdisciplinaire sur /'Enfant (CIEN), na França, primeiro como metodologia clínica e, posteriormente, ampliada como prática de pesquisa. A conversação tem sido utilizada em diversas pesquisas que articulam psicanálise e educação e tem se mostrado uma metodologia importante para o trabalho tanto com alunos, quanto com docentes e pais, como mostram os trabalhos de Santiago e Assis (2015), Lima et al (2015b), Diniz et al (2010), entre outros. Santiago (2008) nos adverte de que o trabalho da conversação na escola tem como desafio incluir a dimensão pulsional, a alteridade no lugar do ideal pedagógico e intervir nos impasses escolares a fim de "permitir um movimento sobre o que se cristaliza como impossível e como sintoma" (Santiago, 2008, p. 9). Lacadée (2000) considera que a principal contribuição da conversação é possibilitar a entrada do sujeito em um discurso.

Para a psicanálise, a adolescência pode ser considerada um tempo lógico de intenso trabalho psíquico, em que o sujeito precisa se inserir no campo social mais amplo, desligando-se da autoridade dos pais. Nessa passagem de um lugar social a outro, ele pode se sentir deslocado, sem lugar, visto que não é mais uma criança, mas ainda não lhe é permitido o acesso ao mundo adulto. Aprendemos com Freud (1905/1996) que a puberdade invade o sujeito e o afeta no campo psíquico de maneira definitiva. Mas, para que seja possível elaborar essas mudanças, o adolescente precisará demorar-se, como nos diz Freud (1910/1980). Há um tempo, próprio a cada um, para a invenção de um saber possível frente à irrupção da puberdade.

No entanto, na atualidade hipermoderna (Lipovetsky, 2004), não há tempo para esperar, o imperativo de gozo exige rapidez. Coelho dos Santos e Lima (2015) apontam que a pós-modernidade inaugura a lógica capitalista conectada ao advento da internet. O modo como os jovens utilizam e se apresentam na internet indicam os efeitos do imperativo de gozo sobre as subjetividades da nossa época. Para as autoras, "os jovens na internet encontram-se desamparados, sem bússola, pois estão sem o suporte de um Outro humanizado. Ficam à deriva, deslizando em um campo sem fronteiras definidas" (Coelho dos Santos \& Lima, 2015, p. 280).

Lacadée (2000) aponta a conversação como uma prática de conexões na qual o adolescente pode entrelaçar corpo e palavra. Para o psicanalista, essa conexão é necessária na adolescência, especialmente na atualidade, em que há maior inconsistência do Outro. Em seu trabalho com os adolescentes, o psicanalista verifica uma demanda de respeito, "testemunha de preocupação de uma certa dignidade para 'fazer bem com o pior' [...]. Mas também do desejo por um discurso, uma escrita de se inscrever num laço ao Outro, a fim de ser reconhecido" (Lacadée, 2000, p. 13). 
Esse desejo de reconhecimento e de inscrição num laço ao Outro justificam a oferta de espaços de acolhimento desse endereçamento, espaços humanizados pela presença do Outro, para além dos espaços virtuais. Como os jovens têm feito esse endereçamento? Como acolher essa demanda atual? Acreditamos que as conversações criam intervalos entre as imagens virtuais, permitindo a emergência da palavra, e, com ela, o sujeito. Assim, escutamos os adolescentes falarem sobre o que fazem na internet, sobre o que buscam nesse espaço, além de discorrerem sobre as formas de interlocução e de transmissão de suas experiências nas redes simbólicas do ciberespaço.

Como exposto anteriormente, apresentaremos neste artigo uma reflexão sobre o saber e a sua transmissão no contexto das tecnologias digitais no tempo lógico da adolescência, tendo como apoio para esta discussão as falas dos adolescentes nas conversações. Para fazer esta reflexão, iniciaremos o nosso percurso teórico tecendo algumas diferenças entre o conhecimento, o saber e a informação; em seguida, buscaremos localizar o estatuto do saber no tempo lógico da adolescência, apresentando fragmentos de conversações com adolescentes, sempre nos pautando pela teoria lacaniana.

\section{Saber, conhecimento e informação: o resgate da experiência para a transmissão}

No atual contexto de intenso fluxo de informações no qual estão imersos os adolescentes, bem como todas as demais camadas etárias da população, que lugar fica devotado ao saber na economia psíquica do sujeito? Para tentar responder esta questão, parece importante introduzirmos uma discussão - a partir de balizas externas à psicanálise - sobre o estatuto do saber a circular hoje pela internet, de modo a cotejá-lo conceitualmente com o que passou a ser moeda corrente na contemporaneidade, a ponto de nomear nossa cultura: a informação. Este cotejamento, entretanto, não estaria completo se deixássemos de considerar outra noção que também se coloca no centro da mesma questão: o conhecimento. Assim, a abordagem da questão do saber poderia ser pensada a partir da tríade saber, conhecimento e informação. É preciso destacar que, sobre os dois últimos termos, há importante discussão contemporânea no âmbito sociológico, que busca compreender o atual estágio civilizatório, seja tomando-o como sociedade do conhecimento, seja como sociedade da informação ${ }^{1}$. Para a presente abordagem, buscaremos acessar a discussão a partir de dois campos em que a questão se mostra essencialmente pertinente: o âmbito disciplinar da ciência da informação e a esfera da filosofia da educação, para, finalmente, dialogarmos com a psicanálise.

A questão conceitual em redor da tríade - saber, conhecimento e informação - parece ter tomado lugar de relevo na contemporaneidade, tendo ocorrido inicialmente a partir dos anos 1950, com a emergência da ciência da informação, quando este campo passa, paulatinamente, a ser compreendido em termos disciplinares. Tal disciplina tem como principal objetivo o reconhecimento, a catalogação e organização de dados - seu objeto -, cujo conjunto passa a ser denominado conhecimento ou informação. 
Em que pesem todos os esforços das discussões conceituais na esfera da ciência da informação, a intrínseca relação entre informação e conhecimento parece ponto pacífico entre muitos estudiosos. Conforme destacam Costa e Xavier, "a informação e o conhecimento são simultaneamente causa e efeito um de si mesmos ( $\operatorname{sic}$ ), numa interação dinâmica em que a sucessão pode ser plenamente invertida, mas não gera nenhuma contradição" (Costa \& Xavier, 2010, p. 80). Assim, nessa relação de causalidade entre os dois termos, a disponibilização da informação promove a geração de conhecimento, que produzirá mais informação e que parece constituir um movimento cíclico, cujo fluxo tende a se manter em função de políticas voltadas para o desenvolvimento em ciência e tecnologia (Costa \& Xavier, 2010). É notável, nesse ponto, a busca de uma filiação direta deste campo com a esfera bem mais ampla das instâncias políticas oficialmente responsáveis pela pesquisa e geração de conteúdos para o conhecimento em geral.

Os paradigmas com relação à informação ainda estão a se formar. E, numa primeira conceituação que nos parece relevante para o campo em questão, o conhecimento, em sua dependência para com a informação, será carregado por seus predicados, devendo esta última ser entendida como sua matéria-prima (Costa \& Xavier, 2010). Neste caso, podemos compreender a informação como o estado bruto, ainda sem algum processamento que irá agrupá-la de forma sistemática na forma do conhecimento.

Para Costa e Xavier (2010), a informação científica não tem como função a mera comunicação de inovações, mas guarda uma potencialidade latente para a produção de conhecimento. Esta produção, entretanto, dependerá de um indivíduo capaz de proceder a um manejo específico em um exercício para sua assimilação. Nesta potencialidade, "toda informação deseja cumprir ao máximo sua própria definição, seu conceito, busca a sua realidade na sua própria ideia" (Costa \& Xavier, 2010, p. 80), pois, na intenção de perenizar sua essência na ideia, encontra mais chances de "sobreviver" na fugacidade do mundo material. Desse modo, a informação seria, em sua essência, conhecimento, ainda que, sendo esta a regra de sua tendência, não a alcance plenamente. O mesmo raciocínio é feito com relação ao conhecimento, pois este se baseia numa relação lógico-causal que, ao pressupor o entrelaçamento conceitual entre os dois termos, permite compreender que "quando um se torna mais semelhante e igualado à sua definição, mais traz o outro para sua plena realização" (Costa \& Xavier, 2010, p. 81).

É importante notar que, em meio a toda esta discussão conceitual, bastante característica do campo da ciência da informação, qualquer referência ao saber está ausente na reflexão.

Numa perspectiva mais crítica e advinda do campo da educação, Bondía parte de uma leitura em que retoma o pensamento filosófico de Walter Benjamin (1892-1940) para propor "pensar a educação a partir do par experiência/sentido" (Bondía, 2002, p. 20). Assim, a partir de uma discussão sobre o significado do termo em diversas línguas europeias modernas, Bondía propõe que a experiência venha a ser definida como "o que nos passa, o que nos acontece, o que nos toca" (Bondía, 2002, p. 21). O autor retoma, então, a letra benjaminiana para refletir que, apesar do 
grande fluxo de fatos que a modernidade passa a perceber, nosso mundo vive um crescente empobrecimento no nível da experiência. $\mathrm{E}$ o excesso de informação é um dos motivos para este esvaziamento de sentido. Para o autor, a informação não é experiência. Indo mais além, ele acrescenta que a informação cancela nossas possibilidades de experiência.

Prosseguindo nesta trilha, Bondía (2002) aponta para os demais fatores que concorrem para que a experiência seja cada vez mais rara. Desse modo, ao lado do excesso de informação, estão o excesso de opinião supostamente crítica, a falta de tempo generalizada e o excesso de trabalho que, conforme destaca, não deve ser confundido com a experiência. Para Bondía, tais características extremas, que poderíamos compreender como da ordem de uma lógica de "excesso-e-falta", impregnam o sujeito moderno que, além de ser informado e opinativo, está sempre agitado, em movimento, é um ser que trabalha e tenta "conformar" o mundo "segundo seu saber, seu poder e sua vontade" (Bondía, 2002, p. 24).

A experiência, entretanto, requer outra atitude, e o sujeito da experiência se mostra bastante antagônico ao sujeito moderno:

(...) o sujeito da experiência seria algo como um território de passagem, algo como uma superfície sensível que aquilo que acontece afeta de algum modo, produz alguns afetos, inscreve algumas marcas, deixa alguns vestígios, alguns efeitos. (...) o sujeito da experiência é sobretudo um espaço onde têm lugar os acontecimentos. (Bondía, 2002, p. 24)

Ao contrário do saber atual baseado nos excessos e na intensidade da fluidez, que tem na informação, a um só tempo, seu mote e seu corolário, o saber da experiência tem nesta última seu próprio método. Sua aquisição implica que este método obedeça ao ritmo em que o sujeito vá respondendo ao que Ihe passa, ao que Ihe aconteça ao longo de sua vida. Assim, esta aquisição de conhecimento resulta da própria experiência que, como método, tende a repetir-se, aprimorandose. Trata-se de um processo em que "vamos dando sentido ao acontecer do que nos acontece" (Bondía, 2002, p. 27).

O que parece proposto, segundo Bondía, pelas teorias do capital humano, são características de uma retórica que se dissemina na atualidade sobre as sociedades da informação ou do conhecimento. Sobre este último, o autor define o conhecimento na época atual como basicamente ciência e tecnologia, essencialmente infinito, impessoal, utilitário ou instrumental. "O conhecimento é basicamente mercadoria e, estritamente, dinheiro..." (Bondía, 2002, p. 27).

A ciência moderna adota a experiência, mas desconfia dela e, sob os auspícios cartesianos, converte-a num "elemento do método" (Bondía, 2002, p. 28), buscando um caminho seguro a ser trilhado. Nesse trajeto, o método experimental se funda, mas à custa dos principais atributos do saber, que, em seu papel de formar e transformar as singularidades da experiência, paulatinamente 
são abandonados. O autor destaca a abundância de artefatos técnicos e a enorme pobreza dessas formas de conhecimento que atuavam na vida humana, nela inserindo-se e transformando-a. Para ele, "o conhecimento moderno já não é o saber ativo que alimentava, iluminava e guiava a existência dos homens, mas algo que flutua no ar, estéril e desligado dessa vida em que já não pode encarnarse" (Bondía, 2002, p. 28).

Assim, numa leitura que obedeça à lógica tecnicista e vise o mero acúmulo de conteúdos, o saber é ignorado e parece fora de questão. De outro modo, uma leitura crítica, como a de Bondía (2002), aponta exatamente para o caráter efêmero da relação do sujeito com a informação e o conhecimento, quando estes se mostram tão atrelados a um processo de mercantilização característico do discurso capitalista (Lacan, 1969-1970/1992). Esta relação não produz mais que a repetição do mesmo. Não traz a experiência da ordem do saber, mas apenas da ordem do experimento, o que tende a planificar a cultura e sufocar a heterogeneidade, a diversidade autêntica dos sujeitos: "se o experimento é genético, a experiência é singular" (Bondía, 2002, p. 28).

Segundo Benjamin (1936/1987), experiência e sujeito são indissociáveis. É preciso que haja alguém em quem algo se inscreva para que haja experiência e, inevitavelmente, para que haja também a sua transmissão. No entanto, como observa Benjamin, é necessário também que, no ato da transmissão, o sujeito que executa a transmissão da experiência se retire parcialmente enquanto tal. É preciso que seja dado espaço para que o sujeito que ouve o que lhe é narrado receba a experiência na forma mais próxima de sua crueza. Há de se evitar a imposição ao ouvinte de um contexto psicológico. Benjamin considera, portanto, que a transmissão de saber envolve dois sujeitos, o que transmite e o que aprende, mas o saber deve ser subjetivado por aquele que aprende.

A noção de "saber da experiência" elaborada por Benjamin pode ser aproximada da noção de saber na teoria psicanalítica. O saber da experiência é uma apropriação subjetiva, e, portanto, ocorre no ritmo próprio de um sujeito. Assim, o que se transmite não coincide necessariamente com o que se aprende, tendo em vista a forma singular de apropriação do saber. O estatuto do saber na psicanálise é o de um saber inconsciente, e, portanto, ele será sempre apreendido de forma singular. A transmissão do saber envolve a apropriação de um saber no campo do Outro. Dessa forma, a transferência é motor do acesso ao saber. Lacan nos adverte de que o saber tem a maior relação com o amor. Todo amor se baseia numa certa relação entre dois saberes inconscientes (Lacan, 19721973/1985, p. 197).

A experiência é o que nos toca, ou seja, ela toca o corpo e produz afetos. Para a psicanálise, o saber também tem relação com o corpo. Ele tem a sua raiz na pulsão e sua apreensão envolve as pulsões de domínio e oral. Há uma satisfação pulsional em aprender, em assimilar o saber (Freud, 1905/1996). Em O Seminário 20, mais, ainda, Lacan esclarece que o estatuto do saber se relaciona com algo a ser "apreendido", tomado do campo do Outro: "É por isso que ele é feito de aprender" (Lacan, 1972-1973/1985, p. 130). O saber, apreendido do campo do Outro, deve ser apreciado, saboreado, e, para tê-lo, "é preciso empenhar a própria pele" (Lacan, 1972-1973/1985, p. 130). 0 
saber é tecido no gozo. O saber confere poder ao sujeito. Existe um gozo na conquista e no exercício do saber.

No esforço de aproximar as noções de conhecimento e informação, descritos pelos autores do campo da Ciência da Informação, da tríade elaborada por Lacan para abordar os registros da realidade psíquica - Real, Simbólico, Imaginário -, levantamos a seguinte hipótese: a informação remeteria predominantemente ao registro simbólico, com o seu infinito deslizamento significante, enquanto o conhecimento corresponderia ao registro imaginário, que, como um ponto de estofo, fecharia um sentido, dando um basta ao deslizamento infinito da cadeia significante. Já o saber estaria referido ao real do gozo. Lacan destaca que "não há informação que fique" (Lacan, 19721973/1985, p. 131), ou seja, a informação não toca o corpo, não "entra na própria pele" (Lacan, 1972-1973/1985, p. 131). Assim, podemos compreender o caráter evanescente e fluido da informação.

$\mathrm{Na}$ atual conjuntura da cultura digital, o predomínio do fluxo informação-conhecimento parece, portanto, impedir que a experiência tenha no saber seu motor propulsor. Tendo em vista as diferenças, que construímos acima, entre informação, conhecimento e saber, passamos a questionar em que medida é possível, para o sujeito contemporâneo inserido na cultura digital, construir um saber. Considerando a relação do sujeito adolescente com o saber, quais as possibilidades de elaboração de um saber no espaço virtual, tendo em vista a inconsistência do Outro?

\section{Algumas considerações sobre o saber na adolescência}

Faz-se necessária uma reflexão sobre as relações que o adolescente estabelece com o saber, a fim de compreender melhor o movimento dos jovens contemporâneos no ciberespaço e o estatuto do saber que perpassa o fluxo de informação, a transmissão e apreensão de conhecimento nesse âmbito. A práxis psicanalítica põe em relevo as implicações fundamentais do saber na transição da adolescência - seja como embaraço angustiante do sujeito diante do não saber, seja sob a forma de significativas transformações em sua relação com o saber, muitas vezes de modo determinante para um deslocamento da fixação sintomática. Nesse sentido, o tema da transmissão intergeracional é de grande valor para a compreensão do que está em jogo no apelo ao Outro que constitui esse tempo da vida.

Como transição que se dá no Outro, a adolescência é a passagem da referência familiar, suporte do sujeito na infância, ao grupo social mais amplo. Nessa travessia, é preciso um desenlace da autoridade parental para que outros laços se estabeleçam. A importância dessa transição para Freud (1909/2015) é explicitada no trecho que se segue:

Desprender-se da autoridade dos pais é uma das realizações mais necessárias e também mais dolorosas do indivíduo em crescimento. É absolutamente necessário que ele o faça, e podemos presumir que isso foi alcançado, em alguma medida, por 
todo aquele que se tornou normal. De fato, o progresso da sociedade baseia-se nessa oposição entre as duas gerações. Por outro lado, há uma classe de neuróticos cuja condição, percebemos, foi determinada pelo fracasso nessa tarefa. (Freud, $1909 / 2015$, p. 420)

Freud esclarece que esse desprendimento depende do progressivo desenvolvimento intelectual da criança. $\mathrm{O}$ conhecimento adquirido a partir da experiência exterior ao núcleo familiar mais restrito leva a criança a se aperceber de que os pais não são infalíveis, perfeitos e onipotentes. Conforme o autor, a criança "conhece outros pais, compara-os com os seus, e pode assim duvidar da natureza única e incomparável que lhes atribui" (Freud, 1909/2015, p. 420). A separação do par parental tem seu início, então, na instalação de uma dúvida - proveniente de um saber obtido no círculo social mais amplo - que conduz, pouco a pouco, à certeza da natureza falível e falha dos pais. Tem-se, assim, uma primeira expansão do Outro parental ao Outro social. Mais tarde, a inconsistência do Outro torna-se questão central e irrevogável para o sujeito que chega à adolescência, tempo da vida em que se apresenta um difícil dilema: endereçar-se ao Outro, lá buscar uma reinscrição simbólica, um lugar como adulto, já ciente de sua inconsistência - ou, com a queda de toda a ilusão, de sua inexistência.

A questão da transmissão geracional na adolescência é também sublinhada por Freud (1914/1996) num texto em homenagem ao colégio onde estudou dos nove aos 17 anos. O autor ressalta o valor da figura do professor como referência substitutiva nessa fase em que a autoridade do par parental declina. Ele acentua o fascínio pela personalidade dos mestres e lembra que, para muitos, os caminhos das ciências passavam apenas através de seus professores (Freud, 1914/1996, p. 248), aludindo, assim, à incomensurável carga afetiva presente na transmissão e na apreensão do saber nesse estágio da vida. Portanto, nesse panorama, a relação do adolescente com o saber faz-se, sobretudo, pela via transferencial. No vácuo deixado pela referência dos pais, mostra-se necessária, para Freud, a entrada em cena de outras referências ligadas ao ideal para nortear os caminhos por onde o saber vai passar.

Contudo, a reflexão freudiana acerca da "psicologia do escolar" já conta mais de 100 anos. Em face das contundentes mutações do laço social transcorridas nesse período, constatamos que o paradigma da transmissão que tem como suporte a transferência não encontra mais as mesmas condições discursivas daquela época para se efetuar. Na contemporaneidade hipermoderna, verificamos uma série de mudanças que acarretam, entre inúmeros aspectos, certa rarefação dos ideais e uma pulverização das referências.

Num mundo tomado pelo imperativo do gozo - repercutido pelos ditames do hiperconsumo, pelos ideais inalcançáveis de felicidade, pela permissividade no âmbito da sexualidade -, constatamos a proliferação dos chamados "novos sintomas", sobretudo nas faixas etárias mais jovens, como expressão das novas formas de relação com o gozo. Os sintomas atuais mostram-se 
pouco afeitos ao saber articulado ao inconsciente, não consistindo num recobrimento do gozo, e mais ligados à dimensão "voraz" do saber (Miller, 2012), valendo-se de uma fixação do gozo. E a essa voracidade, a lógica imposta pelo binômio "informação-conhecimento" parece responder de modo exemplar. Com sua eficácia momentânea, essa lógica parece visar não mais que responder a questões pontuais e efêmeras do sujeito contemporâneo - um sujeito mais afeito ao conhecimento preciso e desvinculado, mais tributário da curiosidade que do saber decantado da experiência, esta última, na maioria das vezes, inclusiva da alteridade.

A voracidade do saber provém da "gulodice" do supereu (Lacan, 1973/2003, p. 528), de sua dimensão tirânica, ou seja, tem a ver com a insatisfação que tudo devora sem jamais se saciar elemento fundante do mal-estar na cultura. Conforme Miller (2012), a criança é particularmente vulnerável a essa voracidade. Esse autor notabiliza a crescente concorrência dos saberes, que competem para determinar qual deles prevalecerá na produção dos sujeitos, sob qual domínio cairá a criança. Ele propõe a expressão "epistemopolítica" para designar a política dos saberes que visam especialmente a criança, que disputam entre si com quais significantes-mestres ela será marcada. Miller sublinha, ainda, o predomínio do "saber-semblante" nesses campos, um saber artificioso sobre o gozo da criança, erguido na mesma matriz do discurso da universidade. Como exemplo, expõe a lógica de uma educação que almeja impor o saber pela via da voracidade, e denuncia a política por trás dessa lógica, visto que se trata da produção de sujeitos: "Trata-se sempre de reduzir, de comprimir, de dominar, de manipular o gozo daquele que chamamos uma criança, para dela extrair um sujeito digno deste nome, quer dizer um sujeito 'assujeitado'"' (Miller, 2012, p. 6).

O saber voraz é o saber como mercadoria, como capital. Como atesta Lacan (19691970/1992), o "tudo-saber" passou ao lugar do mestre, configurando uma "tirania do saber" que traz opacidade à dimensão da verdade. Na "sociedade de consumo", o "material humano" é o sujeito que, assujeitado ao "tudo-saber", tornou-se produto, é consumível (Lacan, 1969-1970/1992, p. 30). Meio de gozo por excelência, o saber como capital pulveriza-se notavelmente pelos meios digitais. Essa vertente do saber abarca o campo ilimitado da informação e distingue-se do saber inconsciente, das trocas simbólicas e da transmissão geracional. Ou, na expressão de Bondía (2002), do saber de experiência.

Quanto ao estatuto do saber na contemporaneidade - época em que o objeto está no zênite² -, Lima (2009) avalia:

O saber na posição de objeto com valor de mercado subverte o desejo e sua relação com o sujeito. Agora não há mais uma impossibilidade estrutural e discursiva do sujeito ter acesso ao saber e ao objeto causa do desejo. O saber é oferecido continuamente como uma promessa de satisfação possível para o sujeito. (Lima, 2009, p. 315) 
A autora argumenta que a entrada do saber no mercado acarreta a anulação da via singular. Se todo o saber é possível - e acessível na palma da mão, nos tablets e smartphones - há um apagamento do desejo e da dimensão do impossível concernente ao singular de cada sujeito. Ou, como expressa Miller (2015), a incidência do virtual na vida dos adolescentes de hoje faz com que o saber, antes depositado nos adultos, esteja automaticamente disponível no toque de uma tela: "O saber está no bolso, não é mais o objeto do Outro" (Miller, 2015, s.p.). Essas transformações acarretam importantes consequências para a adolescência.

Conquanto possamos reconhecer importantes avanços no âmbito das liberdades individuais, a pulverização e a escassez de referências ligadas ao ideal têm suas consequências. $O$ controle esmagador da sociedade disciplinar cede lugar ao imperativo de gozo. A estreita conexão entre o saber e o gozo incide no estatuto do saber na contemporaneidade pela via da voracidade, do excesso desmesurado de informação e do valor do conhecimento como mercadoria - em suma, no enlace entre o discurso do capitalista e o discurso da ciência, do qual resulta a exaltação do saber tecnológico, em detrimento da tradição, da memória, da experiência, das trocas simbólicas em geral.

Considerando as distinções que formulamos entre informação, conhecimento e saber, é possível pensar que o que é veiculado pela via das tecnologias digitais refere-se à informação. Como nos esclarece Lacan (1972-1973/1985): "Que um computador pense, quanto a mim estou de acordo. Mas que ele saiba, quem é que vai dizer isto? Pois a fundação de um saber é que o gozo do seu exercício é o mesmo de sua aquisição" (Lacan, 1972-1973/1985, p. 131).

A internet atende ao mercado, que impõe o consumo imediato de informação. A dimensão de voracidade do saber, proveniente do imperativo de gozo do supereu, encontra na informação o seu produto. A internet libera um enxame de significantes, continuamente, sem intervalo para a apropriação subjetiva. Se a internet pode gerar conhecimento, na medida em que proporciona a veiculação de sentidos, esses sentidos são, por vezes, impostos pelo mercado.

O saber é algo a ser tomado do campo do Outro, e envolve uma apropriação singular, no ritmo próprio a cada um. Ele envolve um gozo com a sua aquisição e com o seu uso. O saber requer um lapso de tempo, um intervalo entre o que se transmite e o que se apreende, tempo de assimilação subjetiva. Consideramos, portanto, a diferença entre o saber que se obtém a partir da presença do Outro e a informação que se obtém a partir do toque de uma tela. A informação não se sustenta no corpo, e, portanto, dissipa-se no tempo.

A prevalência da informação na atualidade é também justificada pelo declínio da transmissão geracional do saber na atualidade. Podemos compreender os impasses da adolescência contemporânea a partir da hipótese de uma pane na transmissão geracional do saber. Instala-se, de maneira cada vez mais abrangente, um gap escancarado entre as gerações, pari passu ao progressivo apagamento da diferença geracional. Isto é, ao mesmo tempo em que há um abismo entre pais e filhos, que obstrui a transmissão, há também uma aproximação ilusória, sustentada no imaginário, decorrente de uma lógica discursiva em que o universo dos adultos tem vestimentas 
adolescentes. Se os pais são tão próximos dos filhos, se compartilham dos mesmos saberes, não há o que se transmitir. Por conseguinte, o apagamento da diferença geracional só vem a intensificar a descontinuidade geracional. Esta é evidente no rechaço, por muitos jovens, de qualquer saber que provenha das gerações mais velhas. Se apenas o saber dos pares interessa, não há qualquer interesse pela passagem a outra geração nem pela ascensão a outros saberes.

Avistamos, então, uma adolescência que equivale cada vez mais a um estado e menos a uma transição. Se não há Outro, que se permaneça no mesmo. Essa dilatação no tempo da adolescência é incentivada por um discurso que associa essa fase à suprema felicidade, época fabulosa em que os objetos do mercado - os gadgets, os produtos da moda - são convocados, em profusão, para o lugar de um objeto que falta. A ausência do impossível e a crença num tamponamento do vazio também estão presentes na relação de muitos adolescentes com o sexo. Entregues à permissividade, eles respondem com "tédio" e "morosidade" (Lacan, 1973/2003) à vivência sexual, afetos que comparecem assiduamente nessa fase, conferindo o tom blasé e entediado de uma juventude que já não se destaca pelo entusiasmo. Mais que um modo de vida transitório, "em espera", descortina-se um "estado adolescente", um estado moroso do qual o sujeito nem sempre sai.

Distinta de um estado, a transição da adolescência carece de uma operação simbólica delicada, que deve lidar, para além da transmissão do saber, com o não saber diante do real da sexualidade. Nessa difícil equação, o apelo ao Outro é imprescindível, o que esbarra em grandes dificuldades nas circunstâncias descritas acima. Diante delas, é preciso inventar um caminho - no mais das vezes, inventar um Outro -, ato que na puberdade está associado à introdução de um saber-fazer com a falta conexo à significação do falo, como veremos a seguir.

\section{Tempo de invenção}

Com base na proposição de Lacan (1962-1963/2005) sobre a conexão entre a maturação do objeto a na puberdade e a formação dos conceitos, Coelho dos Santos (2009) afirma que a maturação do objeto a decorre da promoção do falo na relação entre os sexos. Trata-se, de acordo com essa autora, da tradução lacaniana do que Freud chamou de "reencontro com o objeto" na puberdade. Ela acrescenta:

Admito, por hipótese, que a significação do falo é responsável pelo aparecimento do conceito e requer o ultrapassamento das consequências psíquicas da diferença anatômica entre os sexos. É preciso que entre em jogo a função essencial do vazio para que se possa entrar no universo dos semblantes - isto é, dos papeis sexuais em jogo na encenação da vida amorosa - por uma via diferente do imaginário. (Coelho dos Santos, 2009, s.p.) 
Disso depreendemos que os semblantes "homem" e "mulher", resultantes da promoção do falo nesse momento - da passagem do objeto a por $(-\varphi)$, nos termos de uma temporalidade lógica - podem ser tomados como os primeiros conceitos, para além da imagem fálica predominante até então, inaugurando para o sujeito uma nova maneira de lidar com toda a conceituação.

Quanto a essa novidade que a puberdade ocasiona, Coelho dos Santos (2009) destaca que se pode entrever aí um laço entre sexuação e invenção, uma vez que a alternativa entre ter e não ter o pênis precisa ser ultrapassada na entrada da puberdade. Esse ultrapassamento é possível por meio de um salto lógico, que Lacan sublinha como o surgimento da significação do falo. A autora salienta a conexão entre o tempo lógico da puberdade, o acesso aos conceitos e a invenção:

Somente quando a função do símbolo-falo é articulada à inexistência de um representante da mulher, veremos surgir a função do vazio como causa. É essa operação lógica que permite elevar a dissimetria entre os sexos à dimensão do conceito. Não existe acesso ao conceito sem a invenção singular, isto é, o ato de nomeação que refunda o sujeito, o código e a língua. Nomeação, sexuação e invenção são operações lógicas da mesma natureza. (Coelho dos Santos, 2009, s.p.)

Como se vê, Coelho dos Santos (2009) propõe que o acesso aos conceitos depende de uma operação lógica em que a significação do falo se vincula à assimilação da dissimetria radical entre os sexos - associação que nos remete à cristalização da não relação sexual na adolescência (Lacan, 1974/2003). E isso se efetua mediante um ato de refundação do sujeito, que entendemos como a reinscrição no campo do Outro que a passagem adolescente acarreta.

Nesse sentido, a sexualidade irrompe na puberdade como enigma, com a aparição da não relação sexual. Em face do vazio e do não saber, inventa-se um saber-fazer com o vazio. Essa passagem do vazio à invenção é correlata à atualização da causação do sujeito que se dá na adolescência. Com a maturação do objeto a - "o reencontro do objeto" (Freud, 1905/1996) - faz-se necessário atualizar a operação de separação, o que provoca o reconhecimento da falta no Outro ao mesmo tempo em que proporciona a reinvenção desse lugar.

A tarefa da adolescência é, então, uma tarefa de separação. Portanto, diz respeito às operações de causação do sujeito, alienação e separação, atualizadas nesse momento. Na alienação, ocorre a afânise do sujeito, que é alienado no saber do Outro, inconsciente, e tomado pelo sentido. A separação evoca dialeticamente um saber-fazer com a perda, que a experiência da afânise inaugura na alienação, para operar a extração fundamental de um vazio. "Pela função do objeto $a$, o sujeito se separa, deixa de estar ligado à vacilação do ser, ao sentido que constitui o essencial da alienação" (Lacan, 1964/1998, p. 243). Trata-se da passagem de uma posição subjetiva em que "não se pode saber nada" (Lacan, 1964/1998, p. 212) para outra em que o reconhecimento de uma falha estrutural no saber do Outro permite ao sujeito buscar nesse lugar inconsistente um saber que 
não seja totalitário e obsedante. Como atualização dialética da operação de separação, a adolescência pode propiciar um saber-fazer com a perda para, assim, viabilizar a busca de um saber emancipatório e não totalitário no Outro (Viola, 2016).

Nesse sentido, na adolescência, o movimento de separação da referência familiar e de apelo ao Outro social deve se sustentar na relação do sujeito com o saber. Este é a moeda de troca na transição e na oposição geracional e se faz elemento vital na tarefa do adolescente, que abrange a apreensão do saber e a invenção de um caminho. Compreendemos a invenção que pode advir na adolescência como um arranjo particular construído em torno do não saber que se impõe ao sujeito nesse momento. Segundo Lacan, "invenção significa que encontramos uma coisa boa, já bem instalada num cantinho, ou, dito de outra maneira, que temos um achado" (Lacan, 1971/2009, p. 46). O caráter de "achado" deve-se ao encontro de algo familiar - íntimo ao sujeito, ainda que não sabido -, desvelado na forma de um saber enigmático, um lampejo ligado radicalmente ao gozo. A invenção proporciona ao sujeito uma inscrição singular no Outro, um modo de ali estar e de se posicionar perante o gozo. Embora mantenham estreito parentesco, a invenção não se confunde com o sintoma. Sua potência operatória é proporcional a sua capacidade de favorecer certo deslocamento da posição sintomática, que é uma fixação. Para inventar um modo próprio de passagem pela adolescência, é preciso fazer vacilar a rigidez sintomática.

A maturação do objeto $a$ é a presentificação de um vazio na puberdade, que advém como enigma, um não saber diante da não relação sexual, que se torna questão incontornável para o sujeito. Sendo assim, a maturação pubertária requer um tratamento simbólico. Trata-se do desvelamento de um vazio irredutível - o furo que a sexualidade faz no real (Lacan, 1974/2003) que se torna peremptório na puberdade, momento em que a maturação orgânica não é acompanhada de um saber sobre o sexo. Dito de outra maneira, a maturação do corpo não torna possível a relação sexual. Ao contrário, nesse momento, escancara-se a impossibilidade. Essa conjunção paradoxal de uma maturação no corpo que ratifica uma falta corresponde à maturação do objeto a. Esta é uma designação para a não relação sexual que se desvela na puberdade (Viola, 2016).

Portanto, o não saber é inerente ao despreparo fundamental do ser humano para o real traumático da sexualidade. O não saber concerne ao saber da verdade, um "saber do real", tal como Lacan (1973-1974) o concebe em seu pensamento mais tardio. Seus efeitos perturbadores sobre o adolescente podem desencadear um estado de suspensão marcado por atuações, errâncias ou pela fixação sintomática, inclusive, sob as roupagens dos "novos sintomas". Nesses casos, dificilmente a adolescência é efetivamente atravessada, restando na história de um sujeito como obstáculo, limite - o que assume as mais variadas vertentes, desde a chamada "adolescência prolongada" até a dimensão de evento catastrófico.

Por outro lado, os efeitos desse "saber do real" que advém com a puberdade podem acarretar uma importante modificação na relação com o saber num âmbito mais amplo: o 
adolescente sabe que não sabe, e essa familiaridade com o vazio pode ser transposta a um saberfazer com a falta. Assim, a operação da adolescência, como passagem, requer o deslocamento de um não saber - angustiante e estagnador - a um saber proveniente do Outro - lugar que, em sua ausência, deve ser inventado.

Nesse tempo lógico, a apreensão dos semblantes "homem" e "mulher" (Coelho dos Santos, 2009) - a queda da ilusão de complementariedade entre os sexos - inaugura a entrada no pensamento em conceitos e, por conseguinte, a possibilidade de inventar uma saída própria para cada adolescência. Para tanto, numa época em que o ideal declina e em que o saber se crê total num processo iniciado, como aponta Lacan (1969-1970/1992), com a passagem do discurso do mestre para o discurso da universidade, ocorrida na modernidade -, faz-se necessário, cada vez mais, o reconhecimento local - no "caso a caso", no âmbito familiar, na vida escolar - do singular que se manifesta, muitas vezes de modo perturbador, caótico, sintomático. Esse reconhecimento por parte do Outro - contrário a qualquer perspectiva homogeneizante, rotuladora e normativa de tratamento da adolescência - pode fazer borda, cingir o pulsional que extravasa do corpo, legitimando um "saber haver-se" com o campo do gozo (Lacan, 1968-1969/2008). Trata-se da oferta ao sujeito de um "saber-fazer com isso"3 (Lacadée, 2013) que se apresenta na adolescência, que é transfigurado em matéria-prima para o novo, para a reinvenção de si, preservando-se o que lhe é singular. Na escuta do dissonante que provém das palavras e dos atos dos jovens - o que norteia a direção do tratamento numa psicanálise, mas que deve se estender, como orientação, ao Outro em geral a que o adolescente se dirige: a família, a escola, a sociedade -, dá-se a centelha para o novo que pode constituir um caminho possível (Viola, 2016).

\section{A escuta de adolescentes na escola}

A fim de fundamentar as questões levantadas e avançar na discussão do tema aqui proposto, apresentaremos, a seguir, recortes das falas e elaborações de um adolescente acompanhado em um dos grupos de conversação oferecidos pelo projeto de pesquisa e extensão Conversação na escola: adolescentes e redes sociais.

Lucas $^{4}$, um menino de 13 anos $^{5}$, foi encaminhado para um dos grupos de conversação por apresentar várias "dificuldades escolares". Aluno repetente, ele continua apresentando notas baixas. Além disso, tem comportamento agressivo, ofendendo colegas, desafiando professores e, frequentemente, envolvendo-se em brigas. Segundo relato da psicóloga da escola, Lucas mora sozinho com a mãe e, desde o primeiro ano do Ensino Fundamental, costuma ficar em casa desacompanhado, até que a mãe chegue do trabalho.

No primeiro encontro, os adolescentes são convidados a falar sobre o que gostam de fazer na internet. Lucas revela que gosta muito de videogame. Conta para o grupo sobre as maravilhas de poder construir, com essa ferramenta, seu próprio mundo, erigindo, do nada, uma casa, 
plantações, ou o que quer que sua imaginação possa criar. No entanto, quando perguntado sobre o motivo de jogar tanto, ele responde que é porque fica sozinho e não tem o que fazer.

Quando questionados sobre as redes sociais, todos os componentes do grupo dizem ter, pelo menos, algumas delas. Lucas tem todas. Se o saber escolar não parece ter interesse para Lucas, ele demonstra ter domínio do saber tecnológico. Explica, com muita propriedade, como usar as redes, como se proteger contra contatos maliciosos, e diz conhecer todos os recôncavos da internet, de Snapchat a Deepweeb ${ }^{6}$. No entanto, parece que o confronto com a falta no Outro o angustia. Qualquer "coisa retardada" dita por algum colega convoca Lucas à agressividade. Ele esbraveja: "Ha, ha ha! 'diqueweeb'. Não sabe nem falar". Nomeia os colegas de "idiotas", "inúteis", "viadinhos", etc. Lucas não perde nenhuma oportunidade de ofender os colegas, gerando grande tensão no grupo.

Se a relação do adolescente com o saber acontece pela via transferencial, e Freud destaca aí a importância da figura do mestre no momento em que a autoridade do par parental declina, 0 movimento que Lucas faz é o de apontar, a todo momento, que o rei está nu, destituindo os professores, assim como os pais, de todo o saber que poderia Ihe ser transmitido. Ele diz: "Os professores não querem trabalhar. A professora de geografia só fica de costas escrevendo no quadro ou mexendo no celular. Eles falam pra gente não fazer uma coisa, mas eles mesmos vão lá e fazem. É tipo nossa mãe". No entanto, o caráter afetivo dessa transmissão fica evidente em outra fala: "Quando o professor é escroto e não escuta o que a gente fala, nem adianta. Pode passar exercício que a gente não faz mesmo. Entra por um ouvido e sai pelo outro. E não tem a ver com o tanto de matéria ou ser difícil. É porque o cara é escroto mesmo. O professor de matemática, por exemplo, dá matéria pra caralho, mas ele é legal, ele conversa com a gente na boa. Aí todo mundo estuda". $\mathrm{E}$, dirigindo-se à moderadora da conversação, conclui: "Você, por exemplo, quando você chegou e falou que a gente não podia jogar truco, eu pensei: 'Nó, vai ser paia', mas aí não. Você conversa com a gente, escuta o que a gente fala. É mó legal".

O desejo de ser escutado, patente na fala de Lucas, faz com que ele participe ativamente dos encontros, dando suas opiniões, compartilhando experiências e, com alguma ajuda das intervenções da moderadora da conversação, escutando os colegas e até aprendendo com eles. Num dos encontros, foi combinado que os adolescentes deveriam levar seus videogames para mostrar os jogos preferidos. Lucas condena fortemente a forma de seu colega jogar, no entanto, no fim da atividade ele reconhece: "Cara, eu falei que desse seu jeito ia dar errado, mas deu certo. Foi bom que eu até aprendi com você. Valeu!".

Com o passar dos encontros, outras questões foram surgindo, especialmente as relativas à sexualidade. As diferenças entre os gêneros, orientação sexual, namoro, sexo, masturbação, foram elementos trazidos pelo grupo, muitas vezes associados aos desenhos animados de "zoação" que assistiam no Youtube ou aos strip clubs dos jogos de videogame que costumam jogar, apesar da inadequação etária. A associação livre os levou a falar de seus medos, explícitos em suas falas, como medo de escuro, de dormir com a porta aberta, de dormir com os pés "pra fora do lençol", das 
roupas penduradas no armário quando está escuro, do barulho dos gatos no telhado. E Lucas arremata: "quando eu sinto muito medo, eu acendo a luz e abraço meu touro de pelúcia".

Os temas relativos ao namoro e à sexualidade começam a ser trazidos com mais frequência pelos adolescentes do grupo. Lucas conta que já teve algumas namoradas. Sobre a preocupação da mãe em relação a seus namoros, ele explica: "Minha mãe só preocupa de eu usar camisinha. Eu não sei por que ela se preocupa com isso. Eu já falei 'mãe, eu tenho doze ${ }^{7}$ anos, eu sou uma criança, como que vai rolar isso?' Eu não vou fazer sexo com a menina...". Alice, outra participante do grupo, também fala das preocupações da sua mãe: "Ela sabe que eu namoro e não está nem aí. Mas ela me explica toda hora que tem que usar camisinha porque ela é enfermeira e trabalha com essas coisas". Mas, enquanto Alice fala com orgulho sobre o saber que the transmite a mãe enfermeira, Lucas denuncia o abandono em que se encontra, ao dizer que, para sua mãe, nada sobre o filho the importa, a não ser o uso da camisinha, para evitar lhe trazer um transtorno maior. O amor também aparece no discurso dos adolescentes. Ciúmes, intrigas, provocações, traição e rompimentos são abordados. E Lucas conclui: "Amor é briga e volta, briga e volta..." É impossível não perceber um envolvimento amoroso entre Lucas e Alice. Os dois estão sempre juntos, ora dividindo fones de ouvido, ora se provocando mutuamente, num "briga e volta" que não deixa dúvidas.

Na adolescência, as pulsões que eram, outrora, autoeróticas, passam a se dirigir ao objeto sexual (Freud, 1905/1996), tornando necessário que o sujeito tome o Outro como objeto. O enredamento dessa tarefa está no encontro com a não relação sexual. Para Lacadée (2011), a grande dificuldade da adolescência advém do fato de que, diante do encontro com o real, o sujeito continua se situando num discurso que até ali o estabelecia. Por isso, esse autor atribui à adolescência a qualidade de ser "a mais delicada das transições" (Lacadée, 2011, p. 33). O adolescente precisa construir certa elaboração, certo saber que lhe permita lançar-se na aventura amorosa.

Mas, se a travessia adolescente implica num desenlace da autoridade parental para 0 estabelecimento de novos laços, como fazê-lo quando o laço com o Outro parece precário e marcado pelo abandono, como nos aponta Lucas?

O saber que antes era depositado nos adultos, ou seja, nos educadores - tomando-se aí os pais também como educadores -, pode agora ser acessado com uma simples visita à internet. Se o saber está no bolso (Miller, 2015), será que o que vemos nos dias de hoje é uma autoerótica do saber em contraposição a uma erótica do saber que passava pela relação com o Outro? Como vimos, a informação veiculada nas redes sociais, facilmente acessível através dos smartphones e outros dispositivos portáteis, não pode ser confundida com o saber.

Os adolescentes se vêem, então, hipnotizados pela tela do computador. Jogos eletrônicos, vídeos do Youtube ou do Facebook vêm tamponar o vazio, dando a ilusão de que são eles quem gozam. No entanto, efetivamente, a tela os devolve de novo à solidão, promovendo um apagamento do sujeito. 
Mas esse movimento não seria justamente uma tentativa de fazer consistir um Outro?

Se, na infância, há um Outro consistente, que organiza, orienta e ampara o sujeito, a adolescência é marcada por uma inconsistência do Outro. O declínio do ideal e a rarefação dos referentes simbólicos acabam por empuxar o sujeito ao abandono, tornando necessário que ele se ocupe em encontrar um sentido para sua vida. A adolescência é, assim, o momento em que o sujeito recebe a "notícia" de que o Outro não existe.

É preciso, então, inventar um Outro, dar-Ihe consistência. Nesse sentido, Lacadée (2011) aponta que as janelas do computador são "a janela para a verdadeira vida, em outro lugar, longe de sua família" (Lacadée, 2011, p. 32). O movimento do adolescente no mundo virtual, de site em site, de clique em clique, pode indicar não uma recusa do Outro, mas uma tentativa de Ihe dar consistência, como um Outro onipotente, que tem resposta para tudo (Mena, 2015). No entanto, "nenhuma palavra convém ao que se modifica no corpo do adolescente e no encontro com o Outro sexo" (Lacadée, 2011, p. 75). Ou seja, o gozo com o qual o adolescente se encontra é de impossível tradução. $\mathrm{E}$ a busca incessante por uma resposta muitas vezes deixa o sujeito à deriva, pois a janela abre-se para um oceano sem fim. Como observa Peixoto Lima (2009), ao navegar na internet, os adolescentes circulam numa rede de informações sem autoria, em que o saber assume uma posição de objeto a ser consumido, um saber sem valor de herança. Conforme essa autora, "como uma das figuras da errância adolescente, o internauta é o flaneur virtual. Retira-se das ruas e vagueia sem rumo pela tela. Acessa sítios sem, no entanto, demarcar seu lugar. Acede a saberes sem, no entanto, constituir filiações" (Lacadée, 2011, s.p.). A procura do jovem pela "verdadeira vida" nas águas virtuais dificilmente encontra um ponto de ancoragem.

No penúltimo encontro, dia em que os componentes do grupo realizavam uma festa de despedida, Lucas chega perto de Alice e diz "I love you". Ela ri em tom de zombaria e responde: "Olha isso que o Lucas tá falando!" Ele também ri e sai da sala para beber água. Algum tempo depois, ele e Alice dividiam o fone de ouvido. Lucas, repentinamente, tem um acesso de agressividade, acusa a colega de ter estragado seu fone de ouvido, arranca o fone do ouvido dela dizendo que ela já tinha estragado um outro e que não aceitaria mais isso. Então atira uma carteira no chão e sai de sala. A moderadora da conversação vai até ele. Ela pergunta o que aconteceu. Ele dá a explicação do fone de ouvido. Ela diz: "Estou vendo que você está muito chateado, não acredito que seja só por isso. Me diga, o que foi?". Ao que ele responde: "Você não vai querer saber". Depois aceita falar e diz que está apaixonado, mas que é por outra menina, diz que sofre muito por isso. Tentou falar com a menina, mas não consegue. O problema é que ela não Ihe dá atenção. Ele diz não saber o que fazer. E conclui: "Adolescência é muito difícil". Se, diante do grupo, Lucas se apresenta como um touro bravo, na conversa individual, o menino deixa entrever a delicadeza de sua couraça, revelando a ambivalência que traz em si. Lucas era, ali, seu touro de pelúcia. 
Passando as tardes sozinho em casa, sem o amparo de um adulto, Lucas localiza na menina que elegeu como objeto de amor o mesmo desapreço que encontra na mãe. Conclui, de antemão, que a moderadora da conversação também não se interessaria pelo que ele poderia the dizer.

\section{Considerações finais}

A palavra ofertada aos adolescentes, durante as conversações, permite-nos localizar os diferentes usos que eles fazem da internet. Em alguns grupos, fica evidente a preferência por jogos virtuais, em outros, pelas redes sociais. De toda forma, em todos os grupos, a discussão sobre o uso da internet propicia o surgimento de temas diversos, tais como sexo, encontros amorosos, relações familiares, fama, dinheiro, transgressões, entre outros. Tal fato nos mostra que o uso que cada adolescente faz da internet aponta para o desejo de cada um, para suas fantasias, conflitos, e, em última instância, para as tentativas de elaboração de um saber possível sobre o impossível da relação sexual.

Percebemos, na clínica com adolescentes, que a acolhida de um traço singular, uma fagulha que seja, possibilita puxar um fio de saber que pode conduzir o sujeito, mesmo imerso em certa rarefação simbólica, ao caminho do novo. Esse deslocamento, por menor que seja, condiz com algum distanciamento do ponto de fixidez do sintoma. Não se trata de uma anulação do sintoma, mas de uma torção que possibilita tomar o singular de um modo de gozo por sua potência inventiva, a face do gozo ligada ao saber.

A invenção pode permear as mais variadas manifestações na adolescência, que têm em comum um elemento novo - um novo que é, ao mesmo tempo, antigo, apenso a um saber indissociável do corpo desde a constituição do sujeito. Esse novo que se apresenta pode ser compreendido como um saber-fazer com o vazio e com o sintoma, um saber haver-se com o gozo (Lacan, 1968-1969/2008), um modo particular de contornar o vazio. Evidentemente, trata-se, para muitos sujeitos, de um saber-fazer falho, precário, instável, que vai derrapar muitas vezes diante do real que se presentifica reiteradamente nessa fase. Ainda assim, quando acolhida e reconhecida no encontro do adolescente com o Outro, a invenção pode configurar o detalhe, mesmo ínfimo, que garante uma operação da adolescência. Nesse detalhe, o Outro é fundamental, seja como olhar que vai reconhecer o sujeito em sua reinscrição em direção à idade adulta, seja como apoio balizador, a mão que a sociedade pode dar ao jovem nessa difícil transição.

Todavia, não se pode contar com esse Outro norteador no mundo contemporâneo, em que, de modo geral, nada mais importa afora o gozo de cada um. Se a adolescência subordina-se a uma operação que é inseparável da dimensão do saber - de sua transmissão, apreensão e invenção -, ela enfrenta demasiados desafios no império do gozo, na era do "cada um por si", em que a informação se sobrepõe ao saber. Contudo, mesmo que, aos solavancos, meninos e meninas atravessam a idade adulta. Ou seja, inventa-se, ainda, um Outro. 
Tal fato nos permite pensar que as transformações do mundo contemporâneo podem ser, em larga medida, positivas. Os jovens, em geral, não estão mais submetidos a uma gama estrita e engessadora de ideais de vida, tampouco respondem à rigidez tirânica de um discurso sustentado na moral controladora dos corpos da sociedade disciplinar (Foucault, 1975/2011). A pulverização dos referentes propicia uma pluralização e um arejamento dos modos de vida atuais, o que nos impede de assistir as mudanças do mundo contemporâneo no tocante à adolescência por lentes exclusivamente pessimistas e saudosistas, que levariam a pressupor uma época mais difícil para quem é jovem. Os tempos são outros e melhores, ao menos no que se refere à severidade das normas e ao controle dos corpos. A questão se desloca para o novo que se apresenta nas mais variadas manifestações de despreparo dos sujeitos diante do real da não relação sexual (Lacan, 1972-1973/1985) e da instalação do objeto no zênite do discurso (Lacan, 1970/2003).

Se a adolescência é um tempo lógico marcado pelo encontro com o real do sexo e pela inconsistência do Outro, é também momento propício para a invenção. E quando, para o adolescente, a vida se abre em feroz carrossel ${ }^{8}$, é a palavra que desbrava o caminho em direção à "significação do desejo e da existência" (Lacadée, 2011, p.81). Mas, se o caderno já não tem mais seu lugar cativo junto ao jovem, acreditamos que a conversação, ao dar voz ao sujeito, pode operar como um lugar de construção de uma resposta singular, uma aposta no desejo. Quando Lucas diz não saber o que fazer, pensamos que tal enunciado pode ser escutado como uma possibilidade inventiva, como uma eventual oportunidade de construção de uma outra resposta, que não a da agressividade, para lidar com o Outro, havendo-se com o gozo e com a não relação. Ele mesmo parece concluir tal fato quando, no último encontro, explica o que achou do trabalho: "Eu gostei muito. É porque aqui a gente tem um papo, assim, que não é aquele papo 'na na na na na na'. É um papo que cada um dá sua opinião, tipo falar mesmo".

\section{Notas:}

${ }^{1}$ No momento, não vamos nos enveredar na discussão acerca da pertinência de uso de tais expressões, buscando nos atermos tão somente aos termos que isolamos inicialmente. Nesse sentido, adotamos a expressão cultura digital que, de modo um tanto genérico, cumpre momentaneamente a função de marcar as mudanças experimentadas a partir da difusão das TIC (Tecnologias de informação e comunicação).

${ }^{2}$ Conforme expressão de Lacan (1970/2003).

3 "Saber haver-se com" e "saber fazer com isso" são expressões utilizadas por diferentes tradutores para traduzir do francês "savoir y faire", que não tem tradução exata no português.

${ }^{4}$ Todos os nomes mencionados nesse trabalho foram alterados para se preservar a privacidade dos participantes.

${ }^{5}$ Lucas completou treze anos durante o semestre em que participou do projeto. 
${ }^{6}$ Snapchat é um aplicativo de troca de mensagens cujo diferencial é o curto tempo de exposição das mensagens. Deepweb é o conteúdo exposto na internet que não é indexado pelos mecanismos de busca padrão, ou seja, a surface web.

${ }^{7}$ Nessa passagem Lucas ainda tinha doze anos.

${ }^{8}$ Referência à música "O caderno", de Toquinho e Vinicius de Moraes, lançada em 1983 no LP Casa de Brinquedos.

\section{Referências Bibliográficas}

Benjamin, W. (1936/1987). O Narrador. Magia, Técnica, Arte e Política. Obras Escolhidas I (pp. 197221). São Paulo: Brasiliense (Trabalho original publicado em 1936).

Bondía, J. L. (2002, jan. a abr.). Notas sobre a experiência e o saber de experiência. Revista Brasileira de Educação, 19, 20-28.

Coelho dos Santos, T. (2009, jan. a jun.). Sobre a clínica da psicanálise de orientação lacaniana: dos impasses da sexuação à invenção do parceiro-sinthoma. Ágora, 12(1), 9-26. Recuperado de http://www.scielo.br/scielo.php?pid=S1516-14982009000100001\&script=sci arttext.

Coelho dos Santos, T. \& Lima, N. L. (2015). O crescimento da exposição ao real traumático na adolescência: declínio do pudor no imaginário contemporâneo. Trauma e suas Vicissitudes: Cadernos de Psicanálise. No prelo.

Costa, R. O. \& Xavier, R. C. M. (2010, mai. a ago.). Relações mútuas entre informação e conhecimento: o mesmo conceito? Ciência da Informação, 39(2), 75-83. Recuperado de http://www.scielo.br/scielo.php?script=sci arttext\&pid=S0100-19652010000200006.

Diniz, M.; Torres, M. A.; Itaboray, C. \& Machado, T. (2010). A conversação e a intervenção sobre o mal-estar docente e o abuso sexual infantil. $8^{\circ}$ Colóquio Internacional do LEPSI, 0 declínio dos saberes $e$ o mercado do gozo. Recuperado de http://www.proceedings.scielo.br/scielo.php?script=sci_arttext\&pid=MSC0000000032010000 100040\&lng=en\&nrm=abn.

Foucault, M. (2011). Vigiar e punir: nascimento da prisão. Petrópolis, RJ: Vozes (Trabalho original publicado em 1975).

Freud, S. (1996). Três ensaios sobre sexualidade. In J. Salomão (Trad.). Edição Standard Brasileira das Obras Psicológicas Completas de Sigmund Freud (Vol. 7, pp. 123-252). Rio de Janeiro: Imago (Trabalho original publicado em 1905).

Freud, S. (2015). O romance familiar dos neuróticos. In. P. C. de Souza (Trad.). O delírio e os sonhos na Gradiva, Análise da fobia de um garoto de cinco anos e outros textos (Vol. 8, pp. 419-424). São Paulo: Companhia das Letras (Trabalho original publicado em 1909).

Freud, S. (1980). Contribuições para uma discussão acerca do suicídio. In J. Salomão (Trad.) Edição Standard Brasileira das Obras Psicológicas Completas de Sigmund Freud (Vol. 11, pp. 217218). Rio de Janeiro: Imago (Trabalho original publicado em 1910). 
Freud, S. (1996). Algumas reflexões sobre a psicologia do escolar. In J. Salomão, trad. Edição Standard Brasileira das Obras Psicológicas Completas de Sigmund Freud (Vol. 13, pp. 245250). Rio de Janeiro: Imago (Trabalho original publicado em 1914).

Lacadée, P. (2000). Da norma da conversação ao detalhe da conversação. In: Lacadée, P \& Monier, $\mathrm{F}$ (Orgs.). Le pari de la conversation. Institut du Champs Freudien: CIEN Centre Interdisciplinaire sur I'Enfant. Paris.

Lacadée, P. (2011). O despertar e o Exilio: ensinamentos psicanalíticos da mais delicada das transições, a adolescência. Rio de Janeiro: Contra Capa Livraria.

Lacadée, P. (2013). La vrai vie à l'école : La psychanalyse à la rencontre des professeurs et de l'école. Paris: Éditions Michèle.

Lacan, J. (2005). O seminário, livro 10: a angústia. Rio de Janeiro: Zahar (Trabalho original publicado em 1962-1963).

Lacan, J. (1998). O Seminário, livro 11: os quatro conceitos fundamentais da psicanálise. Rio de Janeiro: Zahar (Trabalho original publicado em 1964).

Lacan, J. (2008). O Seminário, livro 16: de um Outro ao outro. Rio de Janeiro: Zahar (Trabalho original publicado em 1968-1969).

Lacan, J. (1992). O Seminário, livro 17: o avesso da psicanálise. Rio de Janeiro: Zahar (Trabalho original publicado em 1969-1970).

Lacan, J. (2003). Radiofonia. Outros escritos, pp. 400-447. Rio de Janeiro: Zahar (Trabalho original publicado em 1970).

Lacan, J. (2009). O Seminário, livro 18: de um discurso que não fosse semblante. Rio de Janeiro: Zahar (Trabalho original publicado em 1971).

Lacan, J. (1985). O Seminário, livro 20: mais, ainda. Rio de Janeiro: Zahar (Trabalho original publicado em 1972-1973).

Lacan, J. (2003). Televisão. Outros escritos, pp. 508-543.Rio de Janeiro: Zahar (Trabalho original publicado em 1973).

Lacan, J. (1973-1974). O Seminário, livro 21: le non-dupes errent. (Obra ainda não publicada comercialmente).

Lacan, J. (2003). Prefácio a O despertar a primavera. Outros escritos, pp. 557-559. Rio de Janeiro: Jorge Zahar (Trabalho original publicado em 1974).

Peixoto Lima, M. C. (2009). O declínio do mestre e suas relações com o saber na adolescência: novas reflexões sobre a psicologia do escolar. Estilos da clínica, 14(27), 112-123. Recuperado de http://www.revistas.usp.br/estic/article/view/46065

Lima, N. L. (2009). A escrita virtual na adolescência: Os blogs como um tratamento do real da puberdade, analisados a partir da função do romance. (Tese de Doutorado). Programa de Pós-Graduação em Educação, Universidade Federal de Minas Gerais, Belo Horizonte. 
Lima, N. L. (2013). Projeto de Pesquisa e Extensão. Conversação na escola: adolescentes e redes sociais. Belo Horizonte: Departamento de Psicologia da Universidade Federal de Minas Gerais.

Lima, N. L.; Araújo, R. S.; Souza, E. P.; Dias, A. F. G.; B., C. A.; Alves, R. G. S.; Nihari, K. M. \& Marchi, N. S. B. (2015a). Psicanálise e Educação: um tratamento possível para as queixas escolares. Educação \& Realidade, 40(4), 1103-1125.

Lima, N. L.; Barcelos, N. S.; Berni, J. T.; Casula, K. A.; Ferreira, L. P. M.; Figueiredo, R. F.; Maciel, K. N.; Nunes, M. C. C. \& Otoni, M. S. (2015b, set. a dez.). Psicanálise, educação e redes sociais virtuais: escutando os adolescentes na escola. Revista Estilos da Clínica, 20(3), 421-

440. Recuperado de http://pepsic.bvsalud.org/pdf/estic/v20n3/a05v20n3.pdf.

Lipovetsky, G. (2004). Os Tempos Hipermodernos. São Paulo: Barcarolla.

Mena, L. (2015, dez.). O adolescente, o objeto e o Outro. @gente Digital, 10(4), 1-2. Recuperado de http://www.institutopsicanalisebahia.com.br/agente/010/005 luiz mena.html.

Miller, J.-A. (2012, jan.). A criança e o saber. CIEN Digital, 11, 5-9. Recuperado de http://www.institutopsicanalise-mg.com.br/ciendigital/pdf/CIEN-Digital11.pdf.

Miller, J.-A. (2015). Em direção à adolescência. Intervenção de encerramento da 3a jornada do Instituto da Criança. Recuperado de http://minascomlacan.com.br/blog/em-direcao-aadolescencia/.

Santiago, A. L. (2008). O mal-estar na educação e a Conversação como metodologia de pesquisa intervenção na área de psicanálise e educação. Pesquisa-intervenção na infância $e$ adolescência (pp. 113-131). Rio de Janeiro: NAU Editora /FAPERJ.

Santiago A. L. \& Assis, R. M. (2015). O que esse menino tem? Sobre alunos que não aprendem e a intervenção da psicanálise na escola. Belo Horizonte: Sintoma.

Viola, D. T. D. (2016). O momento-limite conceitual: um estudo sobre as implicações sociais e subjetivas do saber na passagem adolescente. (Tese de doutorado). Faculdade de Filosofia e Ciências Humanas, Universidade Federal de Minas Gerais, Belo Horizonte.

Citacão/Citation: De Lima, N. L. et al. (nov. 2015 a abr. 2016). Adolescência e saber no contexto das tecnologias digitais: há transmissão possível? Revista aSEPHallus de Orientação Lacaniana, 11(21), 42-65. Disponível em www.isepol.com/asephallus. doi: 10.17852/1809-709x.2019v11n21p42-65.

Editor do artigo: Tania Coelho dos Santos.

Recebido/Received: 07/02/2016 / 02/07/2016.

Aceito/Accepted: 18/03/2016 / 03/18/2016.

Copyright: (C) 2013 Associação Núcleo Sephora de Pesquisa sobre o moderno e o contemporâneo. Este é um artigo de livre acesso, que permite uso irrestrito, distribuição e reprodução em qualquer meio, desde que o autor e a fonte sejam citados/This is an open-access article, which permites unrestricted use, distribution, and reproduction in any medium, provided the author and source are credited. 